\title{
Brief report: How adolescent personality moderates the effect of love history on the young adulthood romantic relationship quality?
}

\author{
Rongqin $\mathrm{Yu}^{\mathrm{a}, *}$, Susan Branje ${ }^{\mathrm{a}}$, Loes Keijsers ${ }^{\mathrm{a}}$, Wim Meeus ${ }^{\mathrm{a}, \mathrm{b}}$ \\ ${ }^{a}$ Research Centre Adolescent Development, Utrecht University, The Netherlands \\ ${ }^{\mathrm{b}}$ Department of Developmental Psychology, Tilburg University, The Netherlands
}

\section{A R T I C L E I N F O}

\section{Article history:}

Available online 12 March 2014

\section{Keywords:}

Overcontrollers

Undercontrollers

Resilients

Romantic relationship experience

Romantic relationship quality

\begin{abstract}
A B S T R A C T
This study examined the effect of previous romantic relationship involvement on later romantic relationship quality and tested whether adolescents' personality type (i.e., overcontrollers, undercontrollers, resilients) moderated this link. We answered our research questions in a sample of 320 Dutch participants (213 girls) who had a romantic relationship when they were 21 years old. At 12 years of age, their personality types were identified. At 21 years of age, participants reported their current romantic relationship quality (i.e., commitment, exploration, and reconsideration) and indicated the number of romantic relationships they had before. No main effects of the number of romantic relationships on current romantic relationship quality were found. There were significant interaction effects between personality types and the number of romantic relationships on romantic relationship quality. With more romantic relationship experiences, undercontrollers committed less to and explored less in their current romantic relationship. No such link was found for resilients and overcontrollers.
\end{abstract}

(c) 2014 The Foundation for Professionals in Services for Adolescents. Published by Elsevier Ltd. All rights reserved.

Although romantic relationship involvement is common during adolescence, it has been linked to both negative and positive developmental outcomes (e.g., depression, delinquency, self-confidence; Furman \& Collins, 2009; Zimmer-Gembeck, Siebenbruner, \& Collins, 2001). However, it is unknown for which adolescents romantic relationship involvement has negative or positive consequences. In this study, we examined the overall hypothesis that the developmental significance of involvement in romantic relationships might depend on individual personality characteristics (Furman \& Collins, 2009).

More specifically, we focused on the quality of later romantic relationships as an outcome. A recent study showed that adolescents who dated fewer romantic partners during mid-adolescence had better romantic relationship quality in young adulthood (Madsen \& Collins, 2011), suggesting that romantic relationship involvement in adolescence may have adverse effects on later relationship satisfaction. However, a risk group was studied and replicability of the results needs to be tested in other populations. More importantly, individuals' personality types (i.e., overcontrollers, undercontrollers, resilients; Block \& Block, 1980) might moderate the effect of romantic relationship involvement on future romantic relationship quality. In particular, resilients are more capable to develop high-quality relationships than individuals with less resilient personalities

\footnotetext{
* Corresponding author. Research Centre Adolescent Development, Department of Youth and Family, Faculty of Social and Behavioural Sciences, Utrecht University, P.O. Box 80.140, 3508 TC Utrecht, The Netherlands. Tel.: +31302534617.

E-mail address: r.yu@uu.nl (R. Yu).
} 
such as undercontrollers and overcontrollers (Asendorpf, Borkenau, Ostendorf, \& Van Aken, 2001). Moreover, dissolutions of relationships might have more negative effects for individuals who are less able to have a good relationship. Thus, individuals with a less resilient personality type might be more negatively influenced by their romantic relationship dissolutions. The current study tested the replicability of the negative link between romantic relationship involvement and later romantic relationship quality in a normal population and whether adolescent personality moderates the link.

\section{Method}

\section{Participants and procedure}

Participants were 320 Dutch participants (213 girls) who had a romantic relationship when they were on average 21.35 years old $(S D=0.54)$. This sample was part of the younger cohort of an ongoing longitudinal study Conflict and Management of Relationships (Meeus, Van de Schoot, Keijsers, Schwartz, \& Branje, 2010). The present study used data gathered when participants were at age 12 and 21.

\section{Measures}

Age 12 personality types. Adolescents rated their personality on the Quick Big Five questionnaire (Goldberg, 1992; Vermulst \& Gerris, 2005). Five personality dimensions: Extraversion, Agreeableness, Conscientiousness, Emotional stability, and Openness to new experience, were assessed with 6 items each, scored on 7-point Likert scales (from $1=$ very untrue to 7 = very true). Cronbach's $\alpha$ s ranged from .75 to .86 . An earlier study has revealed that three personality types can be constructed directly from the Big Five dimensions with a latent class analysis which is an advanced person-centered analytic strategy grouping individuals into classes (Meeus, Van der Schoot, Klimstra, \& Branje, 2011; Nylund, Asparouhov, \& Muthén, 2007). We adopted this classification from the larger study including our sample. In our sample, there were 151 overcontrollers, 29 undercontrollers, and 140 resilients. See Meeus, Van de Schoot, Klimstra, \& Branje (2011) for mean scores on the Big Five dimensions for each personality type.

Age 21 Relationship history and quality. Number of relationships was obtained by counting the frequency of starting a relationship as reported by participants in a Life History Calendar (LHC; Caspi et al., 1996). LHC is a data-collection method for obtaining reliable retrospective event-history data, which has shown good test-retest reliability and has been considered as an accurate measure of romantic relationship history (Caspi et al., 1996; Asendorpf, \& Van Aken, 1999).

Quality of intimate relationship was assessed with the Utrecht-Management of Identity Commitments Scale (U-MICS; Crocetti, Rubini, \& Meeus, 2008). Participants rated their current romantic relationship commitment (e.g., My partner gives me certainly in life; 5 items, $\alpha=.91$ ), in-depth exploration (e.g., I tried a lot to learn about my partner; 5 items, $\alpha=.78$ ), and reconsideration (e.g., I often think another partner would make my life more interesting; 3 items, $\alpha=.94$ ). Likert-scale ranging from 1 (strongly agree) to 5 (totally disagree) was used and scores were reversely coded.

\section{Results}

Overview of participants' romantic experiences

On average the participants had $0.95(S D=1.17)$ romantic relationships before the current one. In particular, $146(45.6 \%)$ reported having no prior relationship, 90 (28.1\%) reported having had one, 57 (17.8\%) reported having had two, and $27(8.4 \%)$ reported having had three or more relationships. The frequency of prior romantic relationship was not different for boys or girls $(t[320]=0.64, p=.52)$, nor for youths with different personality types $(F[2,319]=0.71, p=.49)$. In addition, there was no significant difference in the distribution of number of relationships by personality types $\left(\chi^{2}[N=320,8]=8.57, p=.74\right)$. To answer our research questions, we conducted linear regression analyses in Mplus (Muthén \& Muthén, 1998-2012) and used robust maximum likelihood (MLR; Satorra \& Bentler, 2001) to take the non-normal distribution of the data into account. Two dummy variables were used to compare personality types, with resilients as the reference group (see Table 1 for descriptive

Table 1

Descriptive statistics and intercorrelations among number of previous romantic relationships and young adults' romantic relationship quality by personality types.

\begin{tabular}{|c|c|c|c|c|c|c|c|c|c|c|c|c|c|c|c|}
\hline \multirow[t]{2}{*}{ Measure } & \multicolumn{5}{|c|}{ Overcontrollers $(n=151)$} & \multicolumn{5}{|c|}{ Undercontrollers $(n=29)$} & \multicolumn{5}{|c|}{ Resilients ( $n=140)$} \\
\hline & $M(S D)$ & 1 & 2 & 3 & 4 & $M(S D)$ & 1 & 2 & 3 & 4 & $M(S D)$ & 1 & 2 & 3 & 4 \\
\hline $\begin{array}{l}\text { 1. No. of Relations } \\
\text { before }\end{array}$ & $0.94(1.14)$ & - & -.01 & .11 & -.10 & $0.72(1.07)$ & - & $-.49^{* *}$ & $-.49^{* *}$ & .34 & $1.01(1.21)$ & - & .00 & $.18^{*}$ & -.06 \\
\hline 2. Commitment & $4.16(0.62)$ & & - & $.21^{* *}$ & $-.38^{* *}$ & $4.38(0.73)$ & & - & $.74^{* * *}$ & -.21 & $4.12(0.65)$ & & - & $.44^{* *}$ & $-.49^{* * *}$ \\
\hline 3. Exploration & $3.93(0.58)$ & & & - & -.10 & $4.14(0.84)$ & & & - & -.15 & $3.97(0.58)$ & & & - & $-.19^{*}$ \\
\hline 4. Reconsideration & $1.50(0.82)$ & & & & - & $1.49(0.99)$ & & & & - & $1.38(0.62)$ & & & & - \\
\hline
\end{tabular}

Note. $M(S D)=$ mean (standard deviation); ${ }^{*} p<.05 ;{ }^{* *} p<.01 ;{ }^{* * *} p<.001$. 
Table 2

Regression analyses summary for number of romantic relationships and personality types in adolescence predicting romantic relationship quality during young adulthood.

\begin{tabular}{|c|c|c|c|c|c|c|c|c|c|}
\hline \multirow[t]{2}{*}{ Predictor } & \multicolumn{3}{|c|}{ Relationship commitment } & \multicolumn{3}{|c|}{ Relationship exploration } & \multicolumn{3}{|c|}{ Relationship reconsideration } \\
\hline & $B$ & $S E(B)$ & $\beta$ & $B$ & $S E(B)$ & $\beta$ & $B$ & $S E(B)$ & $\beta$ \\
\hline \multicolumn{10}{|l|}{ Model 1} \\
\hline Gender & 0.11 & 0.08 & .08 & 0.21 & 0.08 & $.16^{*}$ & -0.18 & 0.09 & $-.11^{*}$ \\
\hline O vs. R & -0.05 & 0.08 & -.04 & -0.03 & 0.07 & -.03 & 0.11 & 0.08 & .07 \\
\hline U vs. R & 0.17 & 0.14 & .08 & 0.22 & 0.16 & .10 & 0.07 & 0.19 & .03 \\
\hline No. relations & -0.04 & 0.04 & -.05 & 0.04 & 0.03 & .06 & -0.03 & 0.04 & -.04 \\
\hline \multicolumn{10}{|l|}{ Model 2} \\
\hline Gender & 0.08 & 0.08 & .06 & 0.18 & 0.07 & $.14^{*}$ & -0.15 & 0.09 & -.09 \\
\hline O vs. R & -0.05 & 0.08 & -.04 & -0.03 & 0.07 & -.03 & 0.11 & 0.08 & .07 \\
\hline U vs. R & 0.11 & 0.13 & .05 & 0.13 & 0.14 & .06 & 0.15 & 0.18 & .06 \\
\hline No. relations & 0.00 & 0.05 & -.01 & 0.08 & 0.05 & $.14^{\dagger}$ & -0.04 & 0.04 & -.05 \\
\hline$(\mathrm{O} \text { vs. } \mathrm{R})^{*}$ No. relations & -0.01 & 0.08 & -.01 & -0.02 & 0.07 & -.02 & -0.05 & 0.08 & -.04 \\
\hline (U vs. R)* No. relations & -0.37 & 0.13 & $-.16^{*}$ & -0.49 & 0.11 & $-.22^{* * *}$ & 0.36 & 0.23 & .13 \\
\hline
\end{tabular}

Note. $B=$ unstandardized regression coefficient; $S E=$ standard error; $\beta=$ standardized regression coefficient; $\mathrm{O}=\mathrm{Overcontrollers;} \mathrm{U}=\mathrm{Undercontrollers;}$ $\mathrm{R}=$ Resilients; ${ }^{\dagger} p<.10 ;{ }^{*} p<.05 ;{ }^{* *} p<.01 ;{ }^{* * *} p<.001$.

statistics and Table 2 for results). In addition, following up the significant interaction effects, sub-group analyses were conducted to examine the effects of number of prior romantic relationships on current romantic relationship quality for both resilient and non-resilient personality types.

\section{Main effects}

The number of prior romantic relationships did not relate to current romantic relationship quality (i.e., commitment, exploration, and reconsideration), while controlling for gender and personality effects (See Table 2, Model 1). We found significant gender differences in the current relationship quality, with girls reported higher exploration and lower reconsideration than boys. Moreover, the three personality types did not differ in the three relationship quality measures.

\section{Interaction effects}

There were significant interaction effects between personality types and number of romantic relationships on commitment and exploration, but not on reconsideration of the current romantic relationship (See Table 2, Model 2). Further, followup subgroup analyses by personality types indicated that undercontrollers' relationship commitment was negatively predicted by number of previous romantic relationships $(n=29, \beta=-.47, p=.02)$. No such link was found for resilients and overcontrollers ( $n=140, \beta=-.01, p=.95$ and $n=151, \beta=-.02, p=.80$, respectively). Also, with more romantic relationship experiences, undercontrollers explored less $(n=29, \beta=-.34, p=.02)$ within their current relationship. No significant association was found for resilients $(n=140, \beta=.15, p=.09)$ and overcontrollers $(n=151, \beta=.11, p=.17)$.

\section{Discussion}

This study showed that, on average, there may be no link between number of previous relationships and later quality of romantic relationships as was found in a previous study (Madsen \& Collins, 2011). However, findings also suggest that for some youths, romantic relationship involvement may have negative consequences: For undercontrollers, but not for overcontrollers and resilients, there were negative effects of prior romantic relationship involvement on later romantic relationship commitment and reconsideration.

The mechanism behind the deleterious effect of former romantic relationships for undercontrollers is not clear. One explanation may be that as undercontrollers' have higher conflict tendencies in romantic relationships than overcontrollers and resilients (Asendorpf et al., 2001), their higher levels of engagement in conflict might lead to more relationship failures which could erode their faith for a good future relationship. Another explanation may be that since undercontrollers have a lower inhibition of emotional responses than others, they fall in love or show love sooner than others, which might lead to more hurts and disappointments when facing relationship break-ups. To understand the potential mechanisms behind the deleterious effect of former romantic relationships on undercontrollers' romantic relationship quality in young adulthood, future research should look into how romantic relationship quality in adolescence relates to personality.

Although the profile of the Big Five for each of the type was similar to other studies, the distribution of personality types differed to some studies in the literature. For instance, Asendorpf and Van Aken (1999) reported having $28 \%$ overcontrollers in their sample whereas in our sample there were $47 \%$ overcontrollers. These variations might be due to a higher percentage of participants with high education levels in our study.

The current study reported a lower number of prior romantic relationships than some other studies (e.g., Connolly \& McIsaac, 2009; Zimmer-Gembeck, Siebenbruner, \& Collins, 2004). Probably this was due to measurement differences. In 
the study of Connolly and McIsaac (2009), for instance, participants were asked to report on their total number of partners, which may involve serious relationships, but also more casual relationships. In the present study, participants were asked to fill in the dates of starting and ending of a relationship in the LHC, which makes it more likely that only serious relationships were reported.

Our study is the first to show that linkages between love history and current relationship quality are moderated by individuals' personality type. Undercontrollers in particular seem to experience the negative consequences of having more romantic relationships. Our results could be used to identify individuals who are especially vulnerable to the deleterious effects of romantic relationship history on future romantic relationship quality.

\section{References}

Asendorpf, J. B., \& Van Aken, M. A. (1999). Resilient, overcontrolled, and undercontrolled personality prototypes in childhood: replicability, predictive power, and the trait-type issue. Journal of Personality and Social Psychology, 77, 815-832. http://dx.doi.org/10.1037/0022-3514.77.4.815.

Asendorpf, J. B., Borkenau, P., Ostendorf, F., \& Van Aken, M. A. G. (2001). Carving personality description at its joints: confirmation of three replicable personality prototypes for both children and adults. European Journal of Personality, 15, 169-198. http://dx.doi.org/10.1002/per.408.

Block, J. H., \& Block, J. (1980). The role of ego-control and ego-resiliency in the organization of behavior. In W. A. Collins (Ed.), Development of cognition, affect, and social relations. Hillsdale: Lawrence Erlbaum Associates.

Caspi, A., Moffitt, T. E., Thornton, A., Freedman, D., Amell, J. W., Harrington, H., et al. (1996). The life history calendar: a research and clinical assessment method for collecting retrospective event-history data. International Journal of Methods in Psychiatric Research, 6, 101-114. http://dx.doi.org/10.1002/ (SICI)1234-988X(199607)6:2\%3C101::AID-MPR156\%3E3.3.CO;2-E.

Connolly, J., \& McIsaac, C. (2009). Adolescents' explanations for romantic dissolutions: a developmental perspective. Journal of Adolescence, 32, $1209-1223$. http://dx.doi.org/10.1016/j.adolescence.2009.01.006.

Crocetti, E., Rubini, M., \& Meeus, W. (2008). Capturing the dynamics of identity formation in various ethnic groups: development and validation of a threedimensional model. Journal of Adolescence, 31, 207-222. http://dx.doi.org/10.1016/j.adolescence.2007.09.002.

Furman, W., \& Collins, W. A. (2009). Adolescent romantic relationships and experiences. In K. H. Rubin, W. Bukowski, \& B. Laursen (Eds.), Handbook of peer interactions, relationships, and groups (pp. 341-360). New York: Guilford.

Goldberg, L. R. (1992). The development of markers for the Big-Five factor structure. Psychological Assessment, 4, 26-42. http://dx.doi.org/10.1037/10403590.4.1.26.

Madsen, S. D., \& Collins, W. A. (2011). The salience of adolescent romantic experiences for romantic relationship qualities in young adulthood. Journal of Research on Adolescence, 21, 789-801. http://dx.doi.org/10.1111/j.1532-7795.2011.00737.x.

Meeus, W., Van de Schoot, R., Keijsers, L., Schwartz, S. J., \& Branje, S. (2010). On the progression and stability of adolescent identity formation. A five-wave longitudinal study in early-to-middle and middle-to-late adolescence. Child Development, 81, 1565-1581. http://dx.doi.org/10.1111/j.1467-8624.2010. 01492.x.

Meeus, W., Van de Schoot, R., Klimstra, T., \& Branje, S. (2011). Personality types in adolescence: change and stability and links with adjustment and relationships: a five-wave longitudinal study. Developmental Psychology, 47, 1181-1195. http://dx.doi.org/10.1037/a0023816.

Muthén, L. K., \& Muthén, B. O. (1998-2012). Mplus user's guide (7th ed.). Los Angeles, CA: Muthén \& Muthén.

Nylund, K., Asparouhov, T., \& Muthén, B. (2007). Deciding on the number of classes in latent class analysis and growth mixture modeling: a Monte Carlo simulation study. Structural Equation Modeling, 14, 535-569. http://dx.doi.org/10.1080/10705510701575396.

Satorra, A., \& Bentler, P. M. (2001). A scaled difference chi-square test statistic for moment structure analysis. Psychometrika, 66, 507-514. http://dx.doi.org/ $10.1007 /$ BF02296192.

Vermulst, A. A., \& Gerris, J. R. M. (2005). QBF: Quick Big Five persoonlijkheidstest handleiding [Quick Big Five personality test manual]. Leeuwarden, The Netherlands: LDC Publications.

Zimmer-Gembeck, M. J., Siebenbruner, J., \& Collins, W. A. (2001). Diverse aspects of dating: associations with psychosocial functioning from early to middle adolescence. Journal of Adolescence, 24, 313-336. http://dx.doi.org/10.1006/jado.2001.0410.

Zimmer-Gembeck, M. J., Siebenbruner, J., \& Collins, W. A. (2004). A prospective study of intraindividual and peer influences on adolescents' heterosexual romantic and sexual behavior. Archives of Sexual Behavior, 33, 381-394. http://dx.doi.org/10.1023/B:ASEB.0000028891.16654.2c. 